\title{
Grand Challenges for Climate Risk Management
}

\author{
Maria Carmen Lemos ${ }^{1 *}$, Nicole Klenk ${ }^{2}$, Christine J. Kirchhoff ${ }^{3}$, Tiffany Morrison ${ }^{4}$, \\ Scott Bremer ${ }^{5}$, Alexandra Paige Fischer ${ }^{1}$, Marta Bruno Soares ${ }^{6}$, Roger Rodrigues Torres ${ }^{7}$ \\ and Jane Mukarugwiza Olwoch ${ }^{8}$
}

${ }^{1}$ School for Environment and Sustainability, University of Michigan, Ann Arbor, MI, United States, ${ }^{2}$ Department of Physical and Environmental Sciences, University of Toronto, Scarborough, ON, Canada, ${ }^{3}$ Department of Civil and Environmental Engineering, School of Engineering, University of Connecticut, Storrs, CT, United States, ${ }^{4} A R C$ Centre of Excellence for Coral Reef Studies, James Cook University, Townsville, QLD, Australia , ${ }^{5}$ Centre for the Study of the Sciences and the Humanities, Faculty of Humanities, University of Bergen, Bergen, Norway, ${ }^{6}$ Sustainability Research Institute, School of Earth and Environment, University of Leeds, Leeds, United Kingdom, ${ }^{7}$ Natural Resources Institute, Federal University of Itajubá, Itajubá, Brazil, ${ }^{8}$ Southern African Science Service Centre for Climate Change and Adaptive Land Management (SASSCAL), Windhoek, Namibia

Keywords: co-production, climate risk, reflexive risk, humanities and climate, climate information governance

The sudden and devastating crisis of the 2020 global pandemic put risk management front and center globally. Many analysts have already highlighted both the commonalities with, and interactions between, the COVID pandemic and climate change. They have also expressed the hope that what we learn about managing risks during the pandemic can help us manage risks related to climate change. Climate change impact shares many characteristics with the pandemic, including its global reach, the way it disproportionately and unfairly affects the poor and the vulnerable, and its non-linear and uncertain character. Both crises also engender the need to address the structural causes of vulnerability at all scales through transformational socioeconomic and political change that improves resilience to all impacts (see for example Ord, 2020). The compound and complex challenge of dealing with multiple stressors at the same time, such as climate change and public health, highlight the need for scholars of risk to think harder about how to both accelerate and scale up the role of scientific knowledge in influencing and informing decisions on the ground.

In the Climate Risk Management section, we work to advance understanding of many of the human and social processes at the heart of managing climate risk: individual perception and behavior, social institutions and organizations, the economics of action and inaction, the assets and capacities needed to build climate resilience, and the power and politics of collective action and transformative change (Morrison et al., 2020). Yet, while advancing understanding of climate risk management and urging others to act-including climate scientists, politicians, and policymakers-many social scientists have been less willing themselves to move from observing and representing to intervening and acting. This reluctance is challenging, because social science scholars have a vital role in designing and testing solutions that manage and reduce the risk of climate change impact. Hence, our goals for the Climate Risk Management section are both about discovery and understanding as well as about how to create actionable knowledge in just and effective ways. It is with these goals in mind that, as co-editors, we crafted a number of research topics to guide the focus of the Section (https://www.frontiersin.org/journals/climate/ sections/climate-risk-management). But within and beyond these topics, we highlight three grand challenges we believe have been less explored and which can further guide our ambition for the section: (1) harnessing social science knowledge toward action and resilience, (2) understanding risk in a reflexive and consequential way, and (3) bridging the social sciences and the humanities to understand and manage risk. 


\section{HARNESSING SOCIAL SCIENCE KNOWLEDGE TOWARD ACTION AND RESILIENCE}

There is still much we do not know about climate impact and dealing with risk. But there is enough we do know that still fails to inform action. The literature focusing on social aspects of climate change mitigation, vulnerability, and adaptation has grown substantially since "the human dimensions of climate change" emerged as a separate field 30 years ago (Lemos et al., 2019). Bringing different perspectives and social sciences disciplines together over time, the social study of climate change has embraced inter- and later trans-disciplinary approaches to co-producing knowledge addressing cross-cutting issues such as resilience, risk, development, and security (Bremer and Meisch, 2017; Lemos et al., 2018, 2019). While these efforts have advanced knowledge, there has been relatively less focus by social scientists on understanding and evaluating when, how and to what effect this collective knowledge has influenced or informed decision-making at the individual, national and international levels (see for example, Vang Rasmussen et al., 2017; Flagg and Kirchhoff, 2018; VanderMolen et al., 2020). This critical gap in our understanding of the impact of social sciences on decisionmaking and climate action means we lack sufficient empirical evidence upon which to base strategies to improve usability and use of social science knowledge. One reason for the gap may be that there has not been enough transdisciplinarity in the social studies of climate change-although social scientists have called for transdisciplinarity in climate and environmental sciences, for example. Many social scientists of climate have been reluctant to inform action both by actively embracing advocacy and by co-producing knowledge with practitioners and policy makers on the ground. Another reason is the limited number of cases empirically evaluating the impact of social science initiatives on decision-making and action (see, for example, Bremer et al., 2019). Hence, we suggest a specific focus on understanding the connection between knowledge and action. Potential research questions within this topic include:

\section{Co-producing Knowledge}

Understanding and testing effective ways of co-producing knowledge-through meaningful interactions between researchers, knowledge intermediaries, and users-to inform risk management while exploring: (a) what quality and credibility means when doing so, and (b) what constitutes success, and how can we best evaluate it. Questions include: how can we assess the quality of different knowledges and knowledge production processes for risk management? Whose responsibility is it to assess quality and success and according to what procedures and criteria? Do climate risks introduce new categories of knowledge that deserve alternative quality assurance? How can appropriate, legitimate, and feasible forms of co-production be effectively implemented? In what ways is co-produced knowledge more useful than knowledge that is not co-produced? How are outcomes improved through co-production compared to other knowledge production approaches?

\section{Accelerating and Scaling Up Actionable Knowledge}

Understanding the drivers and pathways for scaling up coproduction and the use of climate knowledge (both from the physical and social sciences) to inform decision-making. How do we accelerate and scale up the production of actionable knowledge? How do we empirically test alternative practices, through networks and partnerships with policy-makers and practitioners? How can funding best support and increase the production and scaling up of actionable knowledge?

\section{Governing Climate Risk and Knowledge}

Understanding the range of governance agendas, structures, networks, and discourses that frame and shape how climate science and knowledge are produced and used in supporting action-empirically, theoretically and normatively. What institutions, processes, networks, and actors can help foster action and support resilience? How can we stimulate and broaden participation and deliberation in the governance of climate science and knowledge use? How do we strengthen accountability at various levels of intervention and action? How do we effectively include and broaden participation of those impacted by climate change to achieve their goals?

\section{Justice, Equity and Ethics in Knowledge Creation and Use}

Engaging with issues of fairness, justice, and power in producing and deploying knowledge is particularly important when thinking about the politics of who wins and loses with climate change impact and response. How do we ensure that marginalized and vulnerable parties co-produce and act upon knowledge to achieve their goals? How can we foster inclusive co-production of knowledge that accounts for indigenous and local knowledge? How can we best manage and regulate access to climate knowledge and information to protect those most vulnerable?

\section{UNDERSTANDING RISK IN A REFLEXIVE AND CONSEQUENTIAL WAY}

Scientific research and its resulting technologies, scientists' framings of problems and solutions, and the large-scale fieldbased experiments that scientists use to test new ideas and products can themselves contribute to anthropogenic risks. We have seen this in the cases of genetic engineering, nuclear energy, geoengineering, and pesticides, which have been perceived by society as both solutions and new risks. In the context of climate change, techno-scientific responses to narrowly defined risks can prove maladaptive, actually exacerbating risks. For example, large-scale work to raise and armor riverbanks against projected increases in flooding in Bangladesh also cut off the waters essential for irrigated agriculture and replenishment of the lakes with fish, forcing local communities to sabotage these stop-banks (Haque et al., 2017). Anthropogenic risks can be assessed through reflexive introspection, which, in turn, can alter the activities that created these risks to begin with (Giddens, 1990; Beck, 
1992). For example, social concerns about nuclear power risk have led to increased regulation of the industry and curtailment of its expansion, altering the course of modernization and supporting the emergence of concepts such as sustainability and the precautionary principle that focus on preventive measures to decrease levels of risk.

In the climate arena, science is rapidly transforming the way risks are assessed and governed in many of our institutions; infiltrating their practices, rules, norms and social, and cognitive ways of representing climate impacts (see e.g., Sheridan, 2012; Sherpa, 2014; Totin et al., 2018). Climate change uncertainties are altering the way institutions understand and respond to previously well-known risks, de-stabilizing the traditional metrics of hazards and exposure, and undermining claims to control risks, with implications for public trust in institutions (Renn, 2011; Sheridan, 2012). Moreover, new scholarship has challenged the reliance on Western scientific knowledge alone and promoted Indigenous and place-based knowledge systems, problem framings, and potential solutions (Berkes, 2012; Ravera et al., 2019). In encounters with Indigenous knowledge holders, knowledge co-production practitioners are recasting global environmental change research as an issue of knowledge sovereignty, drawing attention to research practices and resource allocation that are allied to ongoing Indigenous people's movements and land-based initiatives (Latulippe and Klenk, 2020). Citizen Science and crowd-funding science have also attracted attention lately as a solution to close the gap between professional science gathering and the public (Wildschut and Zijp, 2020). The Climate Risk Management section encourages work focusing on iterative processes of reflective questioning and assessing of the role of science (natural and social) in the management and governance of climate risks from different perspectives. Potential research questions within this topic include:

\section{Understanding and Assessing the Role of Methods in Shaping Outcomes}

Do methods for assessing climate risk management create or exacerbate other climate risks? If yes, how? How do approaches to studying risk create or exacerbate risks that interact with climate risks? How can different methods of climate risk management account for maladaptation, and generate absorptive, adaptive, or transformative responses to change?

\section{Reflexivity}

What reflexive processes can help scientists anticipate risks that may stem from their solutions? What is the role of concepts like Responsible Research Innovation and Social License to Operate? How are reflexive processes and methods implemented and assessed in climate studies on climate risk perception, management, and communication?

\section{Engaged Research and Participatory Methods}

How can participatory research practices in climate risk perception and management restore trust and legitimacy in academic and governance institutions? How is the assessment of climate risk conditioned by processes of governance, power, subjective values, and interests? How can we separate the influence of formal deliberation on climate risk from grassroots debates and narrative networks?

\section{BRIDGING THE SOCIAL SCIENCES AND THE HUMANITIES TO UNDERSTAND AND MANAGE RISK}

The environmental humanities, eco-literature, and art are important to understanding and responding to climate risks, not solely restricted to as representations of scientific knowledgenor as instruments to elicit risk perceptions, envision future scenarios, or communicate risks, but as practices that produce ways of knowing different and complementary to science (see, for example, (Swanson et al., 2008; Goralnik et al., 2015). Art is widely engaged in and in dialogue with different times, places, cultures, peoples, and predicaments. To gain knowledge through art requires taking an aesthetic stance toward research, writing, and understanding, which in turn, requires paying attention to the affective dimensions of climate risk perception, management, and communication (Head, 2016). For example, creative literature affords us knowledge of many kinds; imagination being a form of simulation, it enables us to "try out" different decisions in a way that we cannot do in real life (Walsh, 1969; Klenk, 2018). And while narrative research has gained prominence as a means of communicating climate risks, its use has been mostly instrumental as opposed to artistic (Paschen and Ison, 2014). Yet, artistic expression is not the servant of science, philosophy, or politics. As a creative act and a way of knowing, artistic expression is singular in enabling us to encounter others as others (different), to imaginatively apprehend and live through situations and events beyond our time and place, to realize another person's experience through an intimate, subtle and delicate discernment of her thoughts and actions (Attridge, 2004). A good story is often a good counsel, giving us good reasons to act in a certain way and guiding decision-making when we are faced with complex problems (Thiele and Young, 2016). Satirical or subversive street art can shine new light on an intractable or undiscovered problem. Reading, writing, performing or installing such stories involves a sensitivity to the all too human and non-human relations that give meaning to climate risk decision-making. Yet little is known about the social and psychological processes through which the arts help people understand and better manage risk. Similarly, little is known about the efficacy of literature and the arts, including street art, as a medium for communicating and encouraging people to act on scientific knowledge. The Climate Risk Management section invites social science research on the role of the arts in individual risk perception, social construction of risk, and risk decision-making. Potential research questions within this topic include:

\section{The Different Ways Narratives Matter}

What knowledge about climate risk perception can visual and narrative storytelling afford us? In what ways can Indigenous narrative research methods be brought into respectful and productive relationship with western traditions of humanities 
scholarship to inform research on climate risk? How might literary techniques, such as discourse analysis, help us understand the metaphors that structure our understanding of climate risk in western scientific research? What is the role of moral emotions such as outrage, hope, and grief in discourses and practices of climate risk management?

\section{Art-Science Collaborations}

For art to function as art, its primary purpose is not to inform or guide action, it is to create plausible alternative worlds. What is the role of knowledge-creation or ArtScience practices in climate risk research and management? How can we learn from previous paradigm changes involving art-science collaborations? How might cognitive science and art be brought to bear on

\section{REFERENCES}

Attridge, D. (2004). The Singularity of Literature. Routledge, 192. doi: 10.4324/9780203420447

Beck, U. (1992). Risk Society: Towards a New Modernity. Translated by Ritter, Mark. London: Sage Publications.

Berkes, F. (2012). Sacred Ecology. 3rd Ed. New York, NY: Routledge: doi: 10.4324/9780203123843

Bremer, S., Haque, M. M., Aziz, S. B., and Kvamme, S. (2019). 'My new routine': assessing the impact of citizen science on climate adaptation in Bangladesh. Environ. Sci. Policy 94, 245-257. doi: 10.1016/j.envsci.2018.12.029

Bremer, S., and Meisch, S. (2017). Co-production in climate change research: reviewing different perspectives. Wiley Interdiscip. Rev. 8:e482. doi: $10.1002 /$ wcc.482

Flagg, J. A., and Kirchhoff, C. J. (2018). Context matters: Context-related drivers of and barriers to climate information use. Clim. Risk Manag. 20, 1-10. doi: 10.1016/j.crm.2018.01.003

Giddens, A. (1990). Consequences of Modernity. Cambridge: Polity Press.

Goralnik, L., Nelson, M. P., Ryan, L., and Gosnell, H. (2015). "Arts and humanities efforts in the US Long-Term Ecological Research (LTER) network: understanding perceived values and challenges," in Earth Stewardship. Ecology and Ethics, Vol. 2, eds R. Rozzi, et al. (Cham: Springer), 249-268. doi: 10.1007/978-3-319-12133-8_16

Haque, M. M., Bremer, S., Aziz, S. B., and van der Sluijs, J. P. (2017). A critical assessment of knowledge quality for climate adaptation in Sylhet Division, Bangladesh. Clim. Risk Manag. 16, 43-58 doi: 10.1016/j.crm.2016.12.002

Head, L. (2016). Hope and Grief in the Anthropocene: Re-Conceptualising HumanNature Relations. London, Routledge. doi: 10.4324/9781315739335

Klenk, N. L. (2018). Adaptation lived as a story. Why it matters what stories we use to tell others' stories with. Nat. Cul. 13, 332-355.

Latulippe, N., and Klenk, N. L. (2020). Making room and moving over: knowledge co-production, Indigenous knowledge sovereignty and the politics of global environmental change decision-making. Curr. Opin. Sustainabil. Sci. 42, 7-14. doi: 10.1016/j.cosust.2019.10.010

Lemos, M. C., Arnott, J. C., Ardoin, N. M., Baja, K., Bednarek, A. T., Dewulf, A., et al. (2018). To co-produce or not to co-produce. Nat. Sustain. 1, 722-724. doi: 10.1038/s41893-018-0191-0

Lemos, M. C., H., Eakin, L., and Dilling, and, J., Worl (2019). Social sciences, weather, and climate change. Meteorol. Monograph. 59, 26.1-26.25. doi: 10.1175/AMSMONOGRAPHS-D-18-0011.1

Morrison, T. H., Adger, N., Barnett, J., Brown, K., Possingham, H., and Hughes, T. (2020). Advancing coral reef governance into the Anthropocene. One Earth 2, 64-74. doi: 10.1016/j.oneear.2019.12.014

Ord, T. (2020). The Precipice: Existential Risk and the Future of Humanity. London: Bloombury Publishing.

Paschen, J.-A., and Ison, R. (2014). Narrative research in climate change adaptation-Exploring acomplementary paradigm for research and governance. Res. Policy 43, 1083-1092. doi: 10.1016/j.respol.2013.12.006 risk management? How do we then relate to art in a way that could support living in a world of many worlds? Or support decision-making about which worlds to choose from (utopia or dystopia?) How do we move beyond tokenistic "Artist in Residency" programs to create more meaningful, productive, and rewarding collaborations between art and science? What is the role of new forms of media, including digital media and social media?

\section{AUTHOR CONTRIBUTIONS}

All authors listed have made a substantial, direct and intellectual contribution to the work, and approved it for publication.

Ravera, F., Reyes-Garcia, V., Pascual, U., Drucker, A. G., Tarrason, D., and Bellon, M. R. (2019). Gendered agrobiodiversity management and adaptation to climate change: differentiated strategies in two marginal rural areas of India. Agric. Hum. Values 36, 455-474 doi: 10.1007/s10460-01809907-w

Renn, O. (2011). The social amplification/attenuation of risk framework: application to climate change. Wires Clim. Change 2:e154. doi: 10.1002/ wcc.99

Sheridan, M. J. (2012). Global warming and global war: Tanzanian farmers' discourse on climate and political disorder. J. East. Af. Stud. 6, 230-245. doi: 10.1080/17531055.2012.669572

Sherpa, P. Y. (2014). Climate change, perceptions, and social heterogeneity in pharak, mount everest region of Nepal. Hum. Organ. 73, 153-161 doi: 10.17730/humo.73.2.94q43152111733t6

Swanson, F. J., Goodrich, C., and Moore, K. D. (2008). Bridging boundaries: scientists, creative writers, and the long view of the forest. Front. Ecol. Environ. 6:499-504. doi: 10.1890/070076

Thiele, L. P., and Young, M. (2016). Practical judgment, narrative experience and wicked problems. Theoria 148, 35-52. doi: 10.3167/th.2016.63 14803

Totin, E., Roncoli, C., Sibiry Traore, P., Somda, J., and Zougmore, R. (2018). How does institutional embeddedness shape innovation platforms? A diagnostic study of three districts in the Upper West Region of Ghana. NJAS - Wageningen J. Life Sci. 84, 27-40 doi: 10.1016/j.njas.2017.07.002

VanderMolen, K., Meadow, A. M., Horangic, A., and Wall, T. U. (2020). Typologizing stakeholder information use to better understand the impacts of collaborative climate science. Environ. Manag. 65, 178-189. doi: 10.1007/s00267-019-01237-9

Vang Rasmussen, L., Kirchhoff, C. J., and Lemos, M. C. (2017). Adaptation by stealth: understanding climate information use across scales and decision spaces in water management in the United States. Clim. Change 140, 451-465. doi: 10.1007/s10584-016-1857-0

Walsh, D. (1969). Literature and Knowledge. Middletown, CT: Wesleyan University Press.

Wildschut, D., and Zijp, H. (2020). The discoveries of citizens running around. Clim. Risk. Manag. 28:100225. doi: 10.1016/j.crm.2020.100225

Conflict of Interest: The authors declare that the research was conducted in the absence of any commercial or financial relationships that could be construed as a potential conflict of interest.

Copyright (C) 2020 Lemos, Klenk, Kirchhoff, Morrison, Bremer, Fischer, Bruno Soares, Torres and Olwoch. This is an open-access article distributed under the terms of the Creative Commons Attribution License (CC BY). The use, distribution or reproduction in other forums is permitted, provided the original author(s) and the copyright owner(s) are credited and that the original publication in this journal is cited, in accordance with accepted academic practice. No use, distribution or reproduction is permitted which does not comply with these terms. 